\title{
Study of Preservatives and Stimulants in Commercial Soft Drinks
}

\author{
Abida Sultana, Robiul Islam, Md. Mazharul Islam, Mohammad Shoeb and Nilufar Nahar \\ Department of Chemistry, University of Dhaka, Dhaka-1000, Bangladesh
}

Received: October 04, 2015; Accepted: February 16, 2016; Published (Web): February 17, 2016

\begin{abstract}
Commercially available soft drinks i.e., Sprite and 7up (lemon) samples of 10 different batches were studied by UV-Vis spectrophotometry to find out the presence of preservative and stimulant. The wavelength of absorption maxima $\left(\lambda_{\max }\right)$ was $224 \mathrm{~nm}$ for sodium benzoate and $272 \mathrm{~nm}$ for caffeine. The soft drink samples were degassed, extracted with HPLC grade water and cleaned up to study sodium benzoate and caffeine content. The average quantity of caffeine was in the range of 22 to $30 \mu \mathrm{g} / \mathrm{ml}$ in Sprite and 20 to $30 \mu \mathrm{g} / \mathrm{ml}$ in 7 up (lemon), whereas the average quantity of sodium benzoate was in the range of 181 to $191 \mu \mathrm{g} / \mathrm{ml}$ in Sprite and 140 to $160 \mu \mathrm{g} / \mathrm{ml}$ in $7 \mathrm{up}$ (lemon) samples. The correlation coefficients of the calibration curves of sodium benzoate and caffeine were found to be 0.9972 and 0.9862 , respectively. Recovery experiment was done by spiking sodium benzoate at $20 \mu \mathrm{g} / \mathrm{ml}$ level with 10 replicate studies. The mean recovery of sodium benzoate was $89.14 \pm 2.14 \%$. The reproducibility and repeatability of the method was very satisfactory with low value of RSD. The present method can be successfully applied for the study of sodium benzoate and caffeine in commercial soft drinks.
\end{abstract}

Key words: Preservative, stimulant, sodium benzoate, caffeine, UV-Vis spectrophotometer

\section{Introduction}

Commercial soft drinks are a combination of different ingredients, including carbonated water, sweetener, artificial flavor, caffeine (Figure 1), coloring agents and preservatives, in particular sodium benzoate (Figure 2). Due to the pleasant taste and ease of availability the demand of commercial soft drinks are increasing all over the world. To meet this demand, preservatives and additives are used to slow down the changes, which cause foods deterioration due to a large number of physical, chemical, enzymatic or biological reactions, and to stop or delay the growth of microorganisms or any deterioration due to microorganisms (Gould, 2000).<smiles>Cn1c(=O)c2c(ncn2C)n(C)c1=O</smiles>

Figure 1. Structure of caffeine.<smiles>O=C([O-])c1ccccc1</smiles>

Figure 2. Structure of sodium benzoate.

The use of sodium benzoate as preservative and caffeine as stimulant in soft drink are very common. Sodium benzoate is bacteriostatic and fungistatic under acidic conditions but daily intake can bring adverse effects on skin such as rash, non-immunological contact urticarial, metabolic acidosis, hyperpnoea and asthma (Bronaugh et al., 1982; Coverly et al., 1998; Lahti et al., 1984; Freedman, 1977).

Caffeine is considered as the most frequently used psychoactive substance in the world (Kapil et al., 2011). It is a xanthine alkaloid compound that acts as a stimulant in humans. But excess intake can bring human health problems especially for pregnant women (James et al., 1983; Kirsten et al., 2003). An overdose of caffeine may cause rapid or irregular heartbeat and breathing problem and sleep disorder (American Psychiatric Association, 1994).

Correspondence to: Nilufar Nahar; Phone: 8801726613813; E-mail: nilufarnahar@ yahoo.com 
Like other countries in the world, consumption of soft drinks and beverages is now a very common habit in Bangladesh. Soft drinks are especially very popular to the children. So, the composition of soft drinks should be regulated by legislations. Determination of food additives and preservatives in soft drinks is mandatory all over the world for ensuring food safety and quality. In continuation of our research on food additives (Abida et al., 2012) in soft drinks and beverages, the present study has been aimed to assess the compliance of the levels of sodium benzoate and caffeine in commercial soft drinks (Sprite and 7up) available from the local market of Dhaka city, Bangladesh.

\section{Materials and Methods}

Sample collection: Commercial soft drink samples, Sprite and 7up (lemon) of ten different batches were collected from different areas of Dhaka city during December 2014 and April 2015 and coded as $\mathrm{SF}_{1}-\mathrm{SF}_{10}$ and $\mathrm{SU}_{01}-\mathrm{SU}_{10}$ for Sprite and 7up, respectively. All of them were in plastic bottle. Samples were stored in a refrigerator.

Chemicals and reagents: HPLC grade water (MilliQ water) which is free from cations, anions and hydrocarbons was used to carry out the study. Standard samples of caffeine and sodium benzoate were obtained by courtesy of Director General of Drug Administration, Government of the People`s Republic of Bangladesh.

Instruments: Double beam Ultraviolet-visible spectrophotometer (Shimadzu, UV-1800), analytical balance (AL 104, Mettler Toledo), vortex mixture (Kebo LabReax-2000) and centrifuge machine (Cowbell) were used.

Preparation of standard solutions: The primary standard $(500 \mu \mathrm{g} / \mathrm{ml})$ solution of sodium benzoate was prepared by dissolving $0.0100 \mathrm{~g}$ of sodium benzoate in a $20 \mathrm{ml}$ volumetric flask by using HPLC grade water. Secondary standard solution $(200 \mu \mathrm{g} / \mathrm{ml})$ was prepared by diluting the primary standard and the working standard solutions of sodium benzoate $(100,80,60,50$, $40,20,10,5,4,2,1,0.5,0.4, \quad 0.2$, and $0.1 \mu \mathrm{g} / \mathrm{ml}$ ) were prepared from secondary standard solution by dilution with HPLC grade water. Similarly, primary
(100 $\mu \mathrm{g} / \mathrm{ml})$, secondary $(50 \mu \mathrm{g} / \mathrm{ml})$ and working standard solutions $(40,20,10,8,6,5,4,3,2,1,0.5$, $0.4,0.2,0.1$ and $0.05 \mu \mathrm{g} / \mathrm{ml})$ of caffeine were prepared with HPLC grade water. Absorptions of working standard solutions of sodium benzoate and caffeine were measured and calibration curves were drawn by plotting absorption vs concentration graph (Figure 3 and 4) and limit of detections were found out.

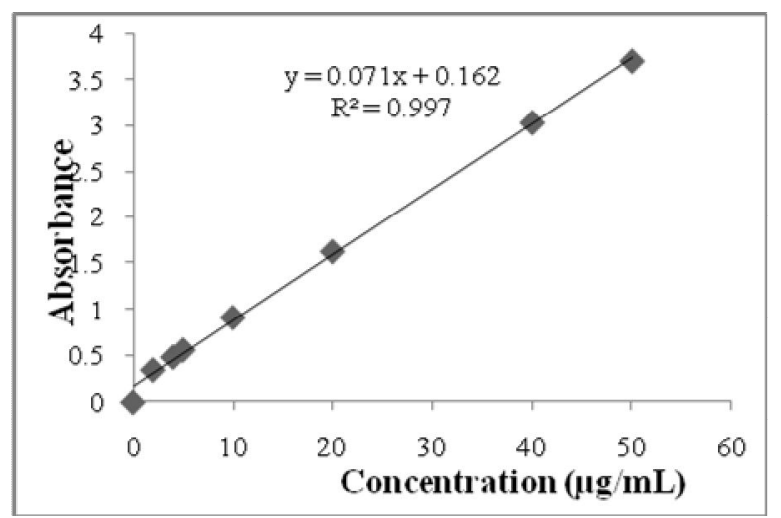

Figure 3. Calibration Curve of sodium benzoate.

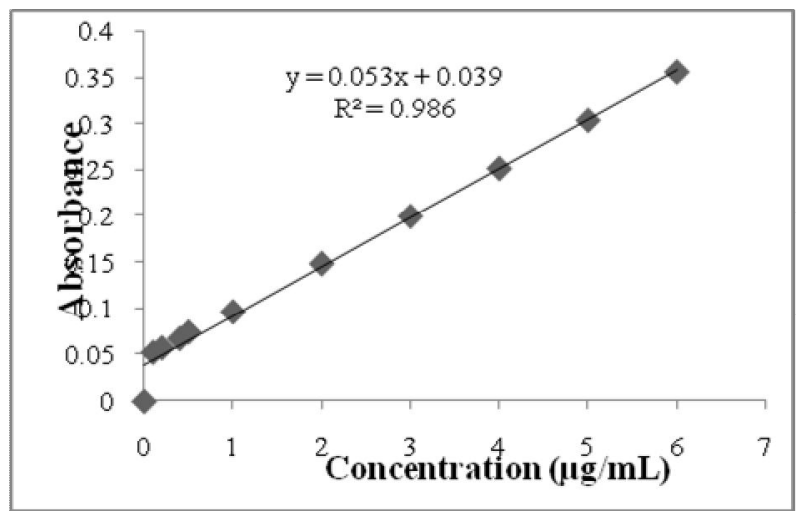

Figure 4. Calibration Curve of caffeine.

Degassing, extraction and clean up: $100 \mathrm{ml}$ of each sample of Sprite and 7up was measured by using a cleaned $100 \mathrm{ml}$ volumetric flask. The sample was filtered by a HPLC grade filter paper $(0.22 \mu \mathrm{m})$ and degassing was done by a degasser machine for about 30 min. The volume of the degassed sample (Table 2) was recorded using burette. $10 \mathrm{ml}$ of the degassed sample was taken in a volumetric flask for dilution. The sample was extracted with HPLC grade water and diluted eight times and homogenized by vortex mixture for $2 \mathrm{~min}$. The solutions were cleaned up by filtering through 
HPLC grade syringe filters $(0.25 \mu \mathrm{m})$. Absorptions of the cleaned extracts (three replicates for each company of each soft drink) were measured and the concentration of sodium benzoate and caffeine were calculated using calibration curves (Figures 3 and 4). Amount of sodium benzoate and caffeine and their relative standard deviations were calculated and the data are presented in the (Tables 3 and 4).

Determination of solid mass: $100 \mathrm{ml}$ of each Sprite and 7up samples with three replications were

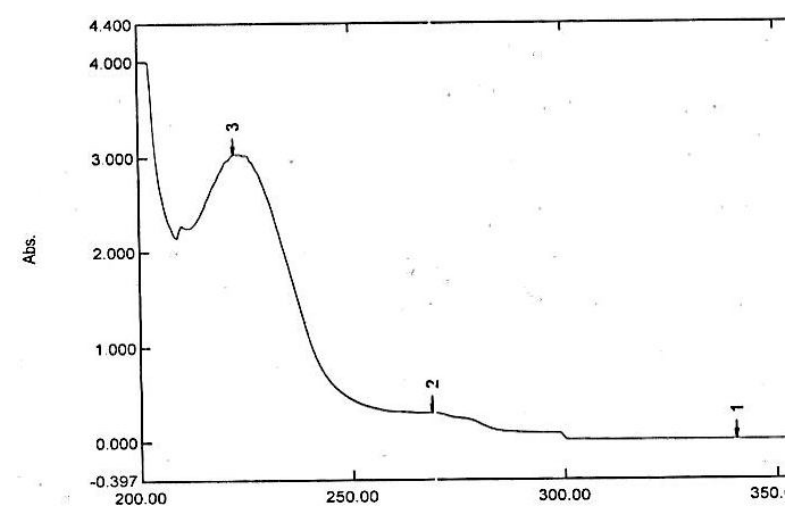

(a)

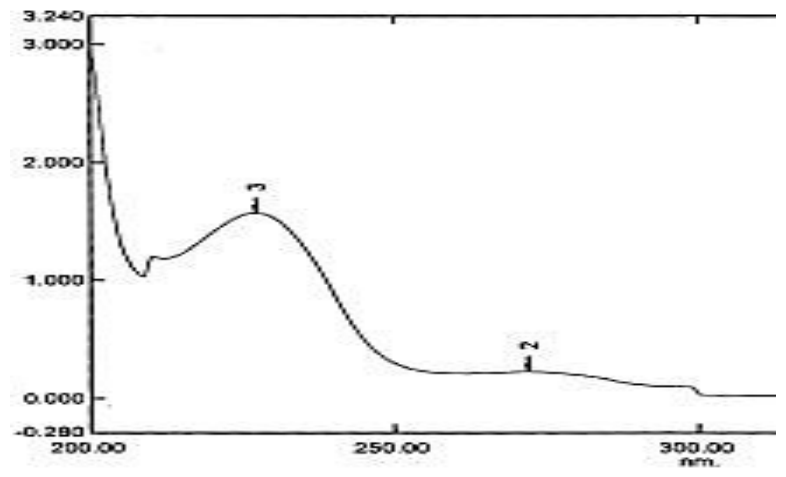

(c) evaporated by a rotary vacuum evaporator at about 35 $40{ }^{\circ} \mathrm{C}$ temperature with the rotation at nearly 200-250 rpm. Then the sample was finally dried to a sticky solid mass by a freeze dryer.

Recovery experiment: Recovery experiments were done by spiking sodium benzoate in HPLC grade water at $20 \mu \mathrm{g} / \mathrm{ml}$ concentration level with ten replications. Percent \& mean recovery and Relative Standard Deviations were calculated and the results are presented in (Table 1).

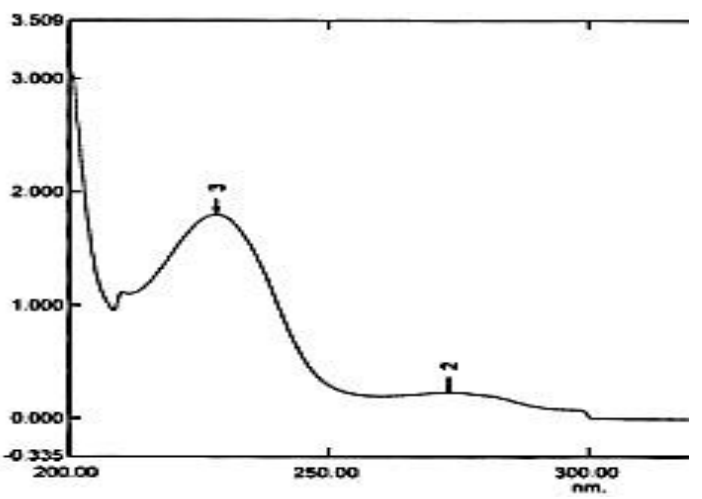

(b)

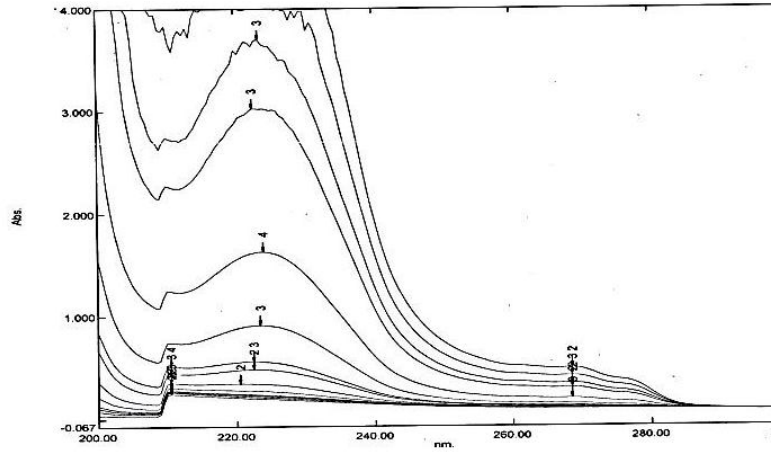

(d)

Figure 5. Spectra of standard sodium benzoate (a), cleaned extract of Sprite (b), cleaned extract of 7up (c) and overlapped (d).

\section{Results and Discussion}

The average volume of dissolved $\mathrm{CO}_{2}$ gas (Table 2) was $6.04 \mathrm{ml}$ for Sprite samples $\left(\mathrm{SF}_{1}-\mathrm{SF}_{10}\right)$ and 7.87 $\mathrm{ml}$ for $7 \mathrm{up} \mathrm{samples}\left(\mathrm{SU}_{1}-\mathrm{SU}_{10}\right)$. The dissolved gas was higher in 7up as compared to Sprite samples. The average solid mass content (Bar Graph 1) was $11.43 \pm$ $0.02 \mathrm{~g} / 100 \mathrm{ml}$ of Sprite samples and $13.09 \pm 0.25 \mathrm{~g} / 100$ $\mathrm{ml}$ for 7up samples, respectively. Relatively higher value of solid mass in 7up indicated higher proportion of additives than Sprite.

The cleaned-up extracts of all the samples of Sprite $\left(\mathrm{SF}_{1}-\mathrm{SF}_{10}\right)$ and $7 \mathrm{up}\left(\mathrm{SU}_{1}-\mathrm{SU}_{10}\right)$ were found to give maximum absorption $\left(\lambda_{\max }\right)$ at $224 \mathrm{~nm}$ for sodium benzoate (Figure 5) and at $272 \mathrm{~nm}$ for caffeine (Figure $6)$. Limit of detection (LOD) of sodium benzoate and caffeine were 1 and $0.1 \mu \mathrm{g} / \mathrm{ml}$ (Figures 5c and 6c) 
showed sensitivity of the modified method. The amount of sodium benzoate (Table 3) in Sprite $\left(\mathrm{SF}_{1}-\mathrm{SF}_{10}\right)$ and $7 \mathrm{up}\left(\mathrm{SU}_{1}-\mathrm{SU}_{10}\right)$ samples were found to be in a range of 181 to $191 \mu \mathrm{g} / \mathrm{ml}$ and 140 to $160 \mu \mathrm{g} / \mathrm{ml}$. According to FAO/WHO Expert Committee on Food Additives (JECFA), the acceptable daily intake (ADI) of sodium benzoate is $0-5 \mathrm{mg} / \mathrm{kg}$ body weight (Vivek et al., 2015). Caffeine content (Table 4) in different batches of Sprite $\left(\mathrm{SF}_{1}-\mathrm{SF}_{10}\right)$ and $7 \mathrm{up}\left(\mathrm{SU}_{1}-\mathrm{SU}_{10}\right)$ were found to be in a range of 22 to $30 \mu \mathrm{g} / \mathrm{ml}$ and 20 to $30 \mu \mathrm{g} / \mathrm{ml}$, respectively, whereas the maximum limit of caffeine specified by FDA is $200 \mu \mathrm{g} / \mathrm{ml}$ (Igelige et al., 2014).
Thus, caffeine and sodium benzoate are used in soft drinks of Bangladesh. So, the daily intake of soft drinks mainly for children should be in limited range to avoid adverse effects on health.

The recovery of the used procedure, which reflects the accuracy of the analytical method, was evaluated by analysing preservative free drink sample spiked with 20 $\mu \mathrm{g} / \mathrm{ml}$ sodium benzoate (Table 1 ). The mean recovery of ten measurements obtained by standard addition approach was found to be $89.14 \pm 2.14$ with relative standard deviation of $2.40 \%$.

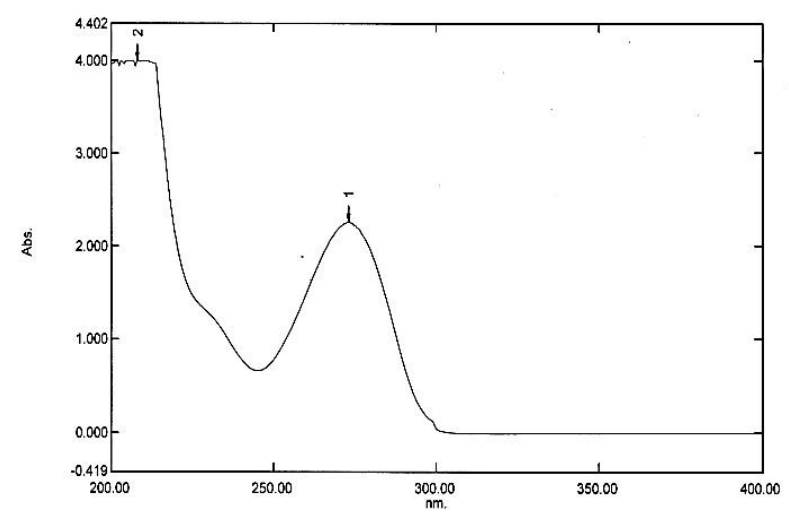

(a)

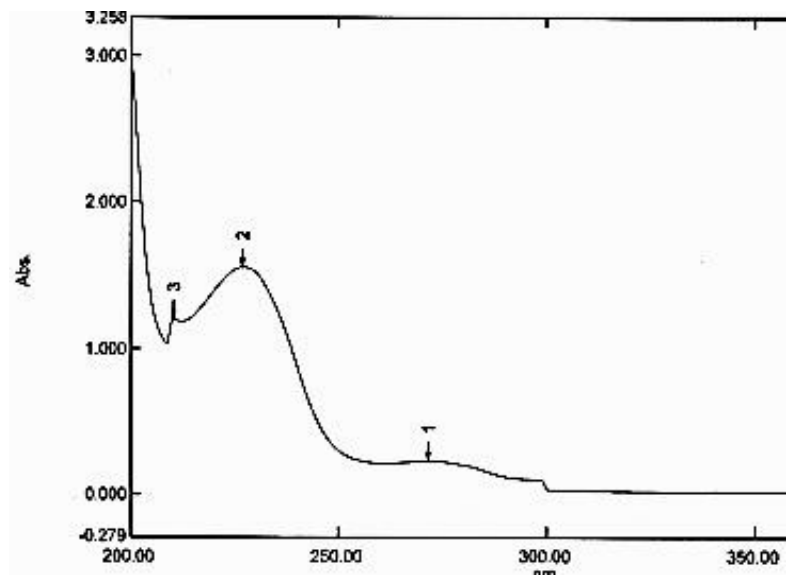

(c)

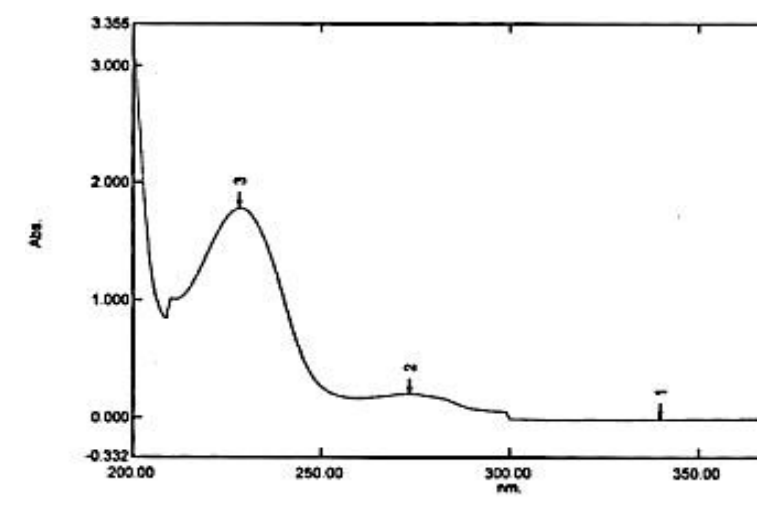

(b)

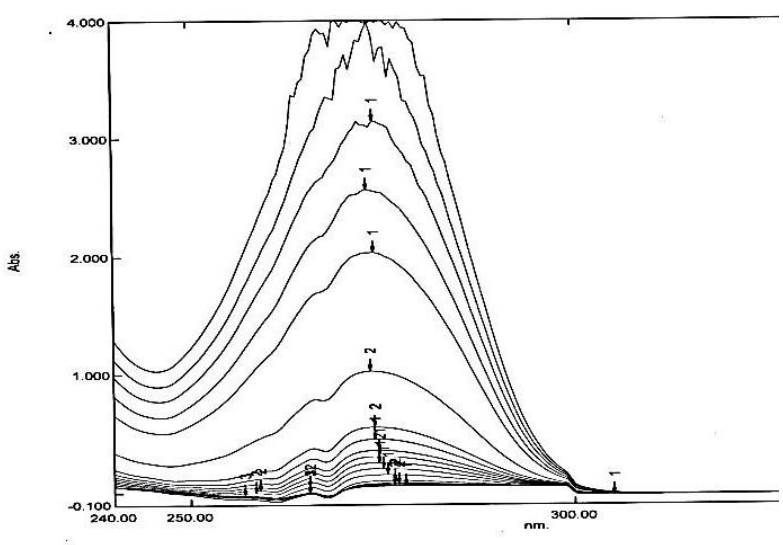

(d)

Figure 6. Spectra of caffeine (a), cleaned extract of Sprite (b), cleaned extract of 7UP(c) and overlapped spectra (d). 
Table 1. Results of recovery experiment.

\begin{tabular}{lccccc}
\hline $\begin{array}{l}\text { Spiking concentration } \\
\text { of sodium benzoate } \\
(\mu \mathrm{g} / \mathrm{ml})\end{array}$ & $\begin{array}{c}\text { Absorbance } \\
\text { at } 224 \mathrm{~nm}\end{array}$ & $\begin{array}{c}\text { Concentration of } \\
\text { sodium benzoate found } \\
(\mu \mathrm{g} / \mathrm{ml})\end{array}$ & $\begin{array}{c}\text { Recovery } \\
(\%)\end{array}$ & $\begin{array}{c}\text { Mean } \\
\text { Recovery } \\
(\%)\end{array}$ & $\begin{array}{c}\text { Relative standard } \\
\text { deviation } \\
(\%)\end{array}$ \\
\hline & 1.451 & 18.04 & 90.20 & & \\
& 1.389 & 17.17 & 85.85 & & \\
& 1.431 & 17.77 & 88.85 & & \\
& 1.468 & 18.28 & 91.40 & & \\
& 1.441 & 17.91 & 89.55 & $89.14 \pm 2.14$ & \\
\hline
\end{tabular}

Table 2. Estimation of the volume of dissolved $\mathrm{CO}_{2}$ gas.

\begin{tabular}{|c|c|c|c|c|c|}
\hline Sample & Code & $\begin{array}{l}\text { Initial volume } \\
\text { of the sample } \\
(\mathrm{ml})\end{array}$ & $\begin{array}{l}\text { Final volume of the } \\
\text { sample }(\mathrm{ml}) \text { after } \\
\text { degassing }\end{array}$ & $\begin{array}{l}\text { Volume of dissolved } \mathrm{CO}_{2} \\
\text { gas }(\mathrm{ml})\end{array}$ & $\begin{array}{c}\text { Average volume of } \\
\text { dissolved } \mathrm{CO}_{2} \text { gas }(\mathrm{ml})\end{array}$ \\
\hline \multirow[t]{10}{*}{ Sprite } & $\mathrm{SF}_{1}$ & \multirow{10}{*}{100} & 94.10 & 5.90 & \multirow{10}{*}{6.04} \\
\hline & $\mathrm{SF}_{2}$ & & 93.50 & 6.50 & \\
\hline & $\mathrm{SF}_{3}$ & & 94.00 & 6.00 & \\
\hline & $\mathrm{SF}_{4}$ & & 94.15 & 5.85 & \\
\hline & $\mathrm{SF}_{5}$ & & 93.70 & 6.30 & \\
\hline & $\mathrm{SF}_{6}$ & & 93.90 & 6.10 & \\
\hline & $\mathrm{SF}_{7}$ & & 93.98 & 6.02 & \\
\hline & $\mathrm{SF}_{8}$ & & 94.20 & 5.80 & \\
\hline & $\mathrm{SF}_{9}$ & & 94.14 & 5.86 & \\
\hline & $\mathrm{SF}_{10}$ & & 93.90 & 6.10 & \\
\hline \multirow[t]{10}{*}{ 7up } & $\mathrm{SU}_{01}$ & \multirow{10}{*}{100} & 90.2 & 9.8 & \multirow{10}{*}{7.87} \\
\hline & $\mathrm{SU}_{02}$ & & 92.5 & 7.5 & \\
\hline & $\mathrm{SU}_{03}$ & & 92.8 & 7.2 & \\
\hline & $\mathrm{SU}_{04}$ & & 94.1 & 5.9 & \\
\hline & $\mathrm{SU}_{05}$ & & 93.6 & 6.4 & \\
\hline & $\mathrm{SU}_{06}$ & & 90.4 & 9.6 & \\
\hline & $\mathrm{SU}_{07}$ & & 92.3 & 7.7 & \\
\hline & $\mathrm{SU}_{08}$ & & 91.8 & 8.2 & \\
\hline & $\mathrm{SU}_{09}$ & & 91.4 & 8.6 & \\
\hline & $\mathrm{SU}_{10}$ & & 92.2 & 7.8 & \\
\hline
\end{tabular}

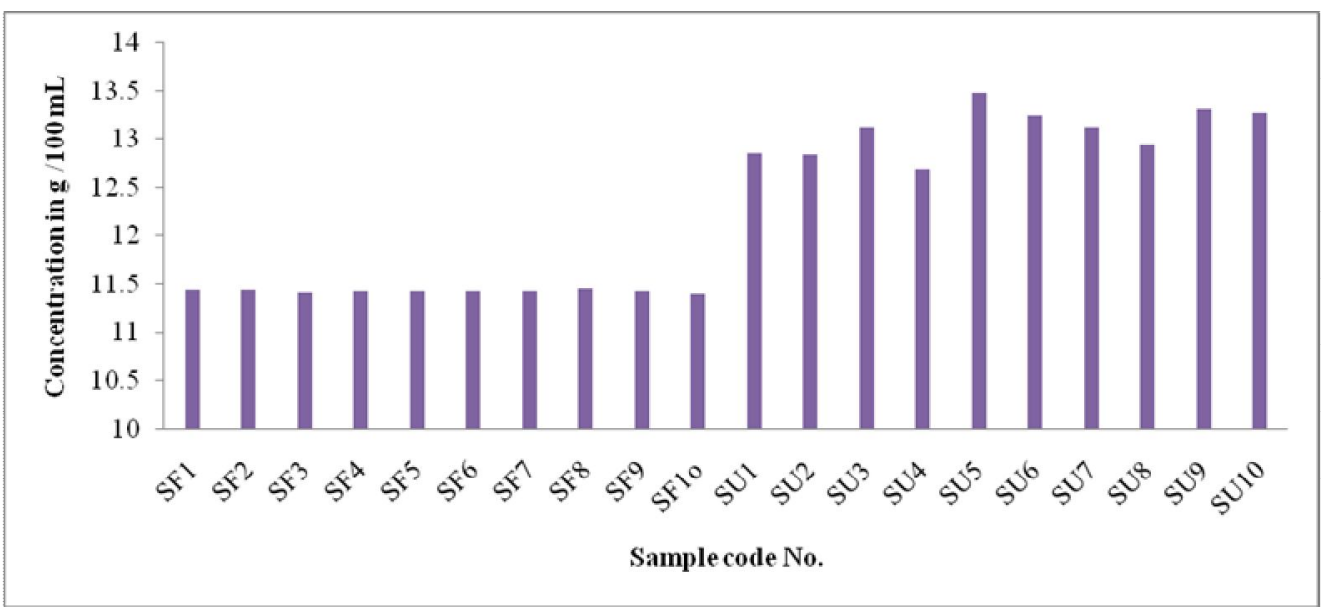

Bar Graph 1. Amount of solid mass in soft drinks. 
Table 3. Determination of amount sodium benzoate.

\begin{tabular}{|c|c|c|c|}
\hline Sample name & Code & $\begin{array}{l}\text { Total amount of sodium benzoate } \\
(\mu \mathrm{g} / \mathrm{ml})\end{array}$ & Relative standard deviation ( $\%$ ) \\
\hline \multirow[t]{10}{*}{ Sprite } & $\mathrm{SF}_{1}$ & $189.55 \pm 2.31$ & 1.22 \\
\hline & $\mathrm{SF}_{2}$ & $190.04 \pm 2.89$ & 1.52 \\
\hline & $\mathrm{SF}_{3}$ & $185.46 \pm 1.59$ & 0.86 \\
\hline & $\mathrm{SF}_{4}$ & $180.92 \pm 3.77$ & 2.08 \\
\hline & $\mathrm{SF}_{5}$ & $181.44 \pm 0.34$ & 0.18 \\
\hline & $\mathrm{SF}_{6}$ & $183.54 \pm 1.94$ & 1.06 \\
\hline & $\mathrm{SF}_{7}$ & $181.06 \pm 1.97$ & 1.09 \\
\hline & $\mathrm{SF}_{8}$ & $187.03 \pm 5.90$ & 3.15 \\
\hline & $\mathrm{SF}_{9}$ & $187.15 \pm 1.84$ & 0.98 \\
\hline & $\mathrm{SF}_{10}$ & $188.01 \pm 0.68$ & 0.36 \\
\hline \multirow[t]{10}{*}{ 7up } & $\mathrm{SU}_{1}$ & $148.18 \pm 4.094$ & 2.76 \\
\hline & $\mathrm{SU}_{2}$ & $161.02 \pm 1.167$ & 0.72 \\
\hline & $\mathrm{SU}_{3}$ & $151.76 \pm 2.224$ & 1.46 \\
\hline & $\mathrm{SU}_{4}$ & $153.29 \pm 1.398$ & 0.92 \\
\hline & $\mathrm{SU}_{5}$ & $158.64 \pm 2.492$ & 1.57 \\
\hline & $\mathrm{SU}_{6}$ & $160.73 \pm 4.634$ & 2.88 \\
\hline & $\mathrm{SU}_{7}$ & $160.16 \pm 3.535$ & 2.20 \\
\hline & $\mathrm{SU}_{8}$ & $165.99 \pm 4.502$ & 2.71 \\
\hline & $\mathrm{SU}_{9}$ & $160.54 \pm 3.091$ & 1.92 \\
\hline & $\mathrm{SU}_{10}$ & $160.35 \pm 3.895$ & 2.42 \\
\hline
\end{tabular}

Table 4. Determination of amount of caffeine.

\begin{tabular}{|c|c|c|c|}
\hline Sample name & Sample ID & $\begin{array}{c}\text { Total amount of caffeine } \\
(\mu \mathrm{g} / \mathrm{ml})\end{array}$ & Relative standard deviation ( \% ) \\
\hline \multirow[t]{10}{*}{ Sprite } & $\mathrm{SF}_{1}$ & $29.65 \pm 1.41$ & 4.76 \\
\hline & $\mathrm{SF}_{2}$ & $27.62 \pm 0.26$ & 0.95 \\
\hline & $\mathrm{SF}_{3}$ & $27.37 \pm 0.95$ & 3.48 \\
\hline & $\mathrm{SF}_{4}$ & $25.86 \pm 1.66$ & 6.45 \\
\hline & $\mathrm{SF}_{5}$ & $22.28 \pm 0.08$ & 0.39 \\
\hline & $\mathrm{SF}_{6}$ & $23.74 \pm 0.23$ & 0.97 \\
\hline & $\mathrm{SF}_{7}$ & $23.74 \pm 1.91$ & 8.07 \\
\hline & $\mathrm{SF}_{8}$ & $25.50 \pm 4.05$ & 15.91 \\
\hline & $\mathrm{SF}_{9}$ & $23.64 \pm 0.23$ & 0.98 \\
\hline & $\mathrm{SF}_{10}$ & $23.44 \pm 0.23$ & 0.97 \\
\hline \multirow[t]{10}{*}{7 up } & $\mathrm{SU}_{1}$ & $19.86 \pm 1.06$ & 0.05 \\
\hline & $\mathrm{SU}_{2}$ & $21.61 \pm 0.83$ & 0.04 \\
\hline & $\mathrm{SU}_{3}$ & $21.26 \pm 1.05$ & 0.05 \\
\hline & $\mathrm{SU}_{4}$ & $29.16 \pm 0.22$ & 0.01 \\
\hline & $\mathrm{SU}_{5}$ & $29.12 \pm 0.76$ & 0.03 \\
\hline & $\mathrm{SU}_{6}$ & $29.46 \pm 1.41$ & 0.05 \\
\hline & $\mathrm{SU}_{7}$ & $29.41 \pm 1.05$ & 0.04 \\
\hline & $\mathrm{SU}_{8}$ & $29.96 \pm 0.79$ & 0.03 \\
\hline & $\mathrm{SU}_{9}$ & $29.16 \pm 0.46$ & 0.02 \\
\hline & $\mathrm{SU}_{10}$ & $29.31 \pm 0.86$ & 0.03 \\
\hline
\end{tabular}

\section{Conclusion}

The described UV-Vis spectrophotometric method for the determination of sodium benzoate and caffeine is satisfactory for a wide range of concentration. This method is very much easy to carry out and also cheaper than other analytical methods such as HPLC (Saad et al., 2005; Isabel et al., 2001),
Spectrophotometry (Founi et al., 2002), Capillary Electrophoresis (Kuo et al., 1997), Gas Chromatography-Mass Spectrometry (Hsui et al., 1999) for sodium benzoate and UV spectrophotometric procedures (Ahmad et al., 2005), HPLC (Aresta et al., 2005), Square Wave Voltammetry (Zen et al., 1997) for caffeine. It can be concluded that the method is sufficiently sensitive and reproducible for routine 
analysis of sodium benzoate and caffeine in soft drinks within a short analysis time.

\section{Acknowledgements}

The authors are grateful to the International Program in Chemical Sciences (IPICS), Uppsala University, Sweden and Higher Education Quality Enhancement Program (HEQEP), Dhaka, Bangladesh for financial support. The Directorate General of Drug Administration Bangladesh is thanked for supplying standard reference samples.

\section{References}

Abida, S., Mohammad, S.H., Mohammad, S., Saiful, I., Mamun, I.R. and Nilufar, N. 2012. Presence of yellow 6, an artificial color additive in orange juice. J. Bangladesh Chem. Soc. 25, 80-86.

Ahmad, H.A., Ali, F.A. and Abdulrahman, A.A.2005. Determination of content levels of some food additives in beverages consumed in Riyadh city. J. King Saud Univ. 18, 99-109.

American Psychiatric Association.1994. Diagnostic and Statistical Manual of Mental Disorders. Fourth Edition. p. 886, ISBN 0-89042-062-9.

Aresta, A., Palmisano, F. and Zambonin, C.G. 2005. Simultaneous determination of caffeine, theobromine, theophylline, paraxanthine and nicotine in human milk by liquid chromatography with diode array UV detection. Food Chem. 93, 177-181.

Bronaugh, R.L., Stewart, R.F. and Congdon, E.R. 1982. Methods for in vitro percutaneous absorption studies II animal methods for human skin. Toxicol. Appl. Pharm. 62, 481-488.

Coverly, J., Peters, L., Whittle, E. and Basketter, D.A. 1998. Susceptibility to skin stinging, non-immunologic contact urticarial and acute skin irritation. Contact Dermatitis 38, 90-95.

Freedman, B.J. 1977. Asthma induced by Sulphur dioxide, benzoate and tartrazine contained in orange drinks. Clin. Allergy 7, 407.

Founi, S.A.V. and Toledo, M.C.F. 2002. Determination of benzoic acid and sorbic acids in Brazilian food. Food Control 13, 125-129. Gould, G.W. 2000. British Med. Bull. 26, 84-96.
Hsui, J. and Youk, M.C. 1999. A simple method for the simultaneous determination of various preservatives in liquid foods. J. Food Drug Anal. 7, 291-304.

Igelige, G., David, E. and Adebiyi, A. 2014. Determination of caffeine in beverages: a review. American J. Engin. Res. 3, 124-137.

Isabel, M.F., Eual, I.M., Paula, B. and Margarida, A.F. 2001. Simultaneous determination of benzoic and sorbic acids in quince jam by HPLC. Food Res. Int. 33, 113-117.

James, J.E. and Stirling, K.P. 1983. Caffeine: a summary of some of the known and suspected deleterious effects of habitual use. British J. Addiction 78, 251-258.

Kapil, K., Sumit, K. and Jyoti, M. 2011. Estimation of caffeine in different beverages by Ultraviolet Spectroscopy. Int. J. Pharm. Life Sci. 2, 1214-1215.

Kirsten, W., Ulrik, K., Bodil, H.B., Morten, H. and Tine, B.H. 2003. Maternal consumption of coffee during pregnancy and stillbirth and infant death in first year of life: prospective study. British Med. J. 326, 420.

Kuo, K.L. and Hsieh, Y.Z. 1997. Determination of preservatives in food products by cyclodextrin-modified capillary electrophoresis with multi wavelength detection. J. Chromatogr. A. 768, 334-341.

Lahti, A. and Maibach, H.I. 1984. An animal model for nonimmunologic contact uriticaria. Toxicol. Appl. Pharmacol. 76, 219-224.

Saad, B., Bari, M.F., Saleh, M.I., Ahmad, K. and Talib, M.K. 2005. Simultaneous determination of preservatives (benzoic acid, sorbic acid, methylparaben and propylparaben) in food stuffs using high-performance liquid chromatography. J. Chromatogr. A. 1073, 393397.

Vivek, R., Aruna, G., Angala, P., Haseena, B. and Jayachandra, R. 2015. Estimated daily intake and exposure of sodium benzoate and potassium sorbate through food products in school children of tirupati, india. Int. J. Pharm. Pharm. Sci. 7, 129-133

Zen, J.M. and Ting, Y.S. 1997. Simultaneous determination of caffeine and acetaminophen by Square Wave Voltammetry. Anal. Chim. Acta. 342, 175-180. 